\title{
Morphology-Based Genetic Diversity Analysis of Sesame Germplasm for Yield and Capsule Characters
}

\author{
Manasi Dash $^{1}{ }^{*}$, Ghanashyam Haibru $^{1}$, Mandakini Kabi ${ }^{1}$, Bansidhar Pradhan $^{1}$, \\ Devraj Lenka ${ }^{1}$ and Sapan Kumar Tripathy ${ }^{2}$
}

${ }^{1}$ Department of Plant Breeding and Genetics, College of Agriculture, Orissa University of Agriculture and Technology, Bhubaneswar, India. Pin-751003

${ }^{2}$ Department of Agril. Biotechnology, College of Agriculture, Orissa University of Agriculture and Technology, Bhubaneswar, India. Pin-751003

*Corresponding author

\section{A B S T R A C T}

\section{Keywords}

Sesamum indicum, Genetic variability, $\mathrm{D}^{2}$ analysis, Canonical analysis

Article Info

Accepted:

12 August 2018

Available Online:

10 September 2018
Forty five Indian sesame genotypes were evaluated for their genetic diversity for seed yield and yield attributing characters as well as capsule shattering characters. The genotypes were classified into five clusters, based on Mahalanobis $\mathrm{D}^{2}$ statistic. Results on inter-cluster distances revealed maximum diversity between genotypes of cluster II and IV. Further, capsule width has the highest contribution to total divergence followed by thousand seed weight, seed number per capsule, capsule length and seed yield per plant indicating their importance in the choice of parents for developing semi shattering genotypes. The present study gives information for most of the characters and their possible use in hybridization program. Crosses can be made between genotypes of cluster II with genotypes of cluster $\mathrm{V}$ to isolate desirable high yielding segregants. Parental combinations from the two clusters with higher value of euclidean distance coefficient could be used for genetic improvement by crossing.

\section{Introduction}

Sesame (Sesamum indicum L.), a diploid species with $2 n=2 x=26$ chromosomes, is a self-pollinated crop. It is an important oilseed crop known for its medicinal properties. The chemical composition of sesame shows that the seed is an important source of oil (50$60 \%)$, protein $(18-25 \%)$, carbohydrates $(13.5 \%)$ and ash (5\%) (Anilakumar et al., 2010; Saeed et al., 2015).
Sesame occupies an area of 7.15 million hectares in the world with a production of 2.8 million tones. Asia contributes more than $68 \%$ of total area and $67 \%$ of total production in the world. In India it is grown in an area of 19.47 lakh hectares with production of 8.66 lakh tons and productivity of $445 \mathrm{~kg} / \mathrm{hectare}$ during 2015-16 which is far below the world average of $535 \mathrm{~kg} /$ hectare which is lower than the world average (Anon, 2016). This indicates the scope for enhancing the productivity of 
this crop by developing high yielding varieties. For rational use of genetic resources, information on genetic diversity within and among closely related crop germplasm is essential. Parents selected on the basis of such study would help in the recombination breeding program for improvement in yield and attributing traits.

It is generally suggested that genetic diversity must form the sound base for selecting parental genotypes for hybridization and development of high yielding varieties rather than geographical diversity (Anuradha and Reddy, 2004 and 2005). Among the several methods of multivariate analysis available to study the genetic divergence in biological population, scientists have extensively used Mohalanobis $\mathrm{D}^{2}$-statistic to quantify genetic divergence among the genotypes in a number of crop plants (Murthy and Arunachalam, 1966). This technique not only presents discrimination among populations on the basis of genetic diversity, but also permits an assessment of the relative contribution of individual characters to the total divergence.

Realizing the importance of development of varieties with high yield potential the present study was carried out to assess the genetic divergence among the sesame germplasm for their effective use as parents in hybridization program. The diversity analysis in the present study aimed at assessing the degree and nature of genetic divergence among forty five varieties of sesame for nine characters with objective of classifying them into groups on the basis of their genetic diversity and selecting divergent genotypes for development of high yielding varieties.

\section{Materials and Methods}

The experimental material comprised of forty five sesame genotypes screened for yield and component traits at the experimental farm of
Orissa University of Agriculture and Technology, Bhubaneswar, India during Rabi 2017-18. The field lay out was done in randomized block design with three replications. Each entry was represented by 2 row plot of $2.0 \mathrm{~m}$ length with a line-to-line spacing of $30 \mathrm{~cm}$ apart. The seed of genotypes were direct seeded in the rows and later thinned to a single seedling per hill at a distance of approximately $10 \mathrm{~cm}$.

All recommended practices were followed to raise a healthy crop. Observations were recorded on nine quantitative traits, viz. days to maturity, plant height, branch number per plant, capsule number per plant, capsule length, capsule width, seed number per capsule, 1000-seed weight and seed yield per plant.

The observations on different quantitative traits were utilized to calculate the genetic divergence and classify the genotypes into different groups following multivariate approach of Mahalanobis $\mathrm{D}^{2}$-statistic and canonical analysis following Rao (1952). After testing for difference between genotypes for each of the nine component characters, a simultaneous test of significance difference in mean values of nine correlated variables of 45 genotypes was carried out using Wilk's Lambda $(\lambda)$ criterion and V-statistics (Rao, 1952). The genotypes were grouped into clusters on the basis of $\mathrm{D}^{2}$ values following Tocher's method as described by Rao (1952). Canonical analysis was done following Anderson (1958) and the $Z_{1}$ and $Z_{2}$ values corresponding to the first two canonical vectors plotted as a supplement to grouping by Tocher's method. Grouping of the population was inferred from their relative dispersion in the $\mathrm{Z}_{1}-\mathrm{Z}_{2}$ graph. Also principal component analysis was carried out for 45 genotypes using nine traits. A total of three principal coordinates were extracted and used for grouping the genotypes. 


\section{Results and Discussion}

The aggregate effect of all the nine characters tested by Wilk's criteria indicated highly significant difference among the genotypes. On the basis of genetic diversity as measured by Mahalanobis' $\mathrm{D}^{2}$-values, all the forty five genotypes were grouped into 5 clusters following Tocher's method (Table 1). Out of these cluster I was the largest comprising of 38 genotypes followed by cluster II consisting of two genotypes and cluster III including three genotypes. Cluster IV and V were monotypic clusters, suggesting the existence of high degree of heterogeneity among the genotypes.

From the average intra- and from inter-cluster distance (Table 1), it is evident that the lowest intra-cluster distance of 242.94 was associated with cluster II, while it was the highest for cluster III $\left(D^{2}=687.94\right)$. Average inter-cluster distance varied from 1205.80 (between cluster I and III) to 2458.20 (cluster II and V). The inter cluster distance was higher than intra cluster distance, indicating the presence of wide genetic diversity among the genotypes under study.

Greater the distance between two clusters, wider the genetic diversity among the genotypes of those clusters. Such highly divergent, high performing genotypes would be of great use in recombination breeding programme in order to get high heterotic recombinants. The lowest inter cluster divergence was noticed between cluster I and III indicating that the genotypes included in them were closely related. Avoidance of selection of parents from genetically homogeneous clusters should be preferred to maintain relatively broad genetic base. So it is expected that crosses between genotypes of cluster II with genotypes of cluster $\mathrm{V}$ will give rise to high yielding segregants, because of highest inter-cluster distance (2458.20).
The cluster mean for each of ten characters (Table 2) indicated that considerable difference existed for all the characters understudy. Cluster I having 38 genotypes was characterized by lower values for branch number per plant, capsule length, thousand seed weight as well as seed yield per plant with moderate values for all other traits. Cluster II exhibited lower values for seed weight per capsule. Cluster III was distinguished for early days to maturity and lowest seed number per capsule. Also Cluster III had the distinction of having taller plants and highest capsule number per plant. Cluster IV having one genotype had the distinction of having long and broader capsules with bold seeds. Cluster V was also a monotypic cluster, characterized for its minimum branch number per plant, capsule number per plant, small plants bearing small capsules, minimum thousand seed weight as well as seed yield per plant. This cluster recorded maximum number of seeds per capsule. The results also indicate that selection of genotypes with high cluster mean values for particular attribute could be used in the hybridization programme for improvement of that character.Similar results were obtained by Sudhakar et al., (2006), Tripathi et al., (2013) and Hika et al., (2015).

Such grouping of genotypes from different genetic origin may be attributed to the unidirectional selection practiced by the breeder in a particular location (Singh and Bains, 1968). However Murty and Arunachalam (1966) have reported that genetic drift and selection, both natural and artificial in different environments could cause greater diversity among genotypes than geographic distances. Probably due to above two factors, the genotypes originating from the different crosses have been clustered together. A key assessment of the observation indicates that none of the clusters contained genotypes with all the desirable traits which could be directly selected and utilized. 
Table.1 Average Intra-(Diagonal) and Inter-Cluster $\left(\mathrm{D}^{2}\right)$ values among 45 sesame genotypes

\begin{tabular}{|c|c|c|c|c|c|}
\hline CLUSTER & I & II & II & IV & V \\
\hline I (38) & $\mathbf{5 1 8 . 0 5}$ & 13900.27 & 1205.80 & 1609.10 & 5397.32 \\
\hline II (3) & & $\mathbf{2 4 2 . 9 4}$ & 19403.35 & 23029.18 & $\mathbf{2 4 5 8 . 2 0}$ \\
\hline III (2) & & & $\mathbf{6 8 7 . 9 4}$ & 1160.14 & 8811.67 \\
\hline IV (1) & & & & - & 11631.37 \\
\hline V (1) & & & & & \\
\hline
\end{tabular}

The number in parenthesis indicate the number of genotypes grouped

Table. 2 Cluster means of nine characters in 45 sesame genotypes

\begin{tabular}{|c|c|c|c|c|c|}
\hline \multirow[t]{2}{*}{ Characters } & \multicolumn{5}{|c|}{ Clusters } \\
\hline & I (38) & II (2) & III (3) & IV (1) & V (1) \\
\hline DM & 86.25 & 85.33 & 85.33 & 86.00 & 86.00 \\
\hline $\mathrm{B} / \mathrm{P}$ & 2.32 & 2.16 & 2.07 & 1.87 & 1.47 \\
\hline $\mathrm{C} / \mathrm{P}$ & 48.13 & 41.43 & 48.56 & 39.87 & 31.20 \\
\hline PH & 88.29 & 88.33 & 96.53 & 72.33 & 86.53 \\
\hline$\overline{C L}$ & 2.55 & 2.90 & 2.52 & 2.92 & 2.28 \\
\hline $\mathbf{C W}$ & 7.29 & 2.90 & 7.96 & 9.01 & 4.19 \\
\hline $\mathrm{SN} / \mathrm{C}$ & 55.75 & 57.97 & 50.47 & 53.27 & 63.67 \\
\hline TSW & 1.47 & 1.34 & 1.16 & 1.89 & 0.97 \\
\hline SY & 1.34 & 2.22 & 2.40 & 1.02 & 0.93 \\
\hline
\end{tabular}

The bold figures indicates minimum and maximum values for each character. 
Table.3 Relative contribution of yield and its components to genetic divergence in 45 sesame genotypes

\begin{tabular}{|c|c|c|c|c|}
\hline Character & Average $\mathbf{D}^{2}$ & $\begin{array}{c}\% \text { Contribution to total } \\
\text { divergence }\end{array}$ & Rank total & Percentage of total rank \\
\hline DM & 2.74 & 0.12 & 7418 & 16.65 \\
\hline $\mathbf{B} / \mathbf{P}$ & 9.17 & 0.45 & 6150 & 13.81 \\
\hline $\mathrm{C} / \mathrm{P}$ & 16.06 & 0.78 & 5532 & 12.42 \\
\hline $\mathbf{P H}$ & 3.87 & 0.19 & 7103 & 15.94 \\
\hline $\mathbf{C L}$ & 44.54 & 2.17 & 4482 & 10.06 \\
\hline $\mathbf{C W}$ & 1580.43 & 76.86 & 2616 & 5.87 \\
\hline SN/C & 125.93 & 6.12 & 3335 & 7.49 \\
\hline TSW & 229.33 & 11.15 & 2887 & 6.48 \\
\hline SY & 44.35 & 2.16 & 5025 & 11.28 \\
\hline
\end{tabular}

Table.4 Average Intra-(Diagonal) and Inter-Cluster coordinate distance among 45 sesame genotypes

\begin{tabular}{|c|c|c|c|c|c|c|c|c|c|}
\hline CLUSTER & I & II & III & IV & V & VI & VII & VIII \\
\hline I (12) & $\mathbf{7 . 8 3}$ & 12.28 & 22.51 & 28.22 & 11.02 & 40.69 & 17.19 \\
\hline II (8) & & & & & & & \\
\hline
\end{tabular}

The bold figures indicates minimum and maximum values for each character. 
Int.J.Curr.Microbiol.App.Sci (2018) 7(9): 1817-1826

Table.5 Cluster means of PCA clusters for nine traits in 45 sesame genotypes

\begin{tabular}{|c|c|c|c|c|c|c|c|c|c|}
\hline & \multicolumn{9}{|c|}{ CLUSTERS } \\
\hline CHARACTERS & I (12) & II (8) & III (11) & IV (6) & V (3) & VI (2) & VII (2) & VIII (1) \\
\hline DM & 86.03 & 86.13 & 85.76 & 86.28 & $\mathbf{8 7 . 5 6}$ & 85.67 & 86.67 & 86.67 \\
\hline B/P & 1.97 & 1.94 & 2.51 & 2.73 & 2.40 & $\mathbf{3 . 1}$ & 1.47 & 2.4 \\
\hline C/P & 40.24 & 36.27 & 53.69 & 62.02 & 46.89 & $\mathbf{7 2 . 9 3}$ & 28.1 & 49.9 .3 \\
\hline PH & 83.32 & 79.58 & 94.39 & 100.56 & 90.48 & $\mathbf{1 0 4 . 7 3}$ & 72.55 & 76.07 \\
\hline CL & 2.65 & 2.64 & 2.39 & 2.49 & 2.71 & 2.61 & 2.62 & $\mathbf{2 . 8 8}$ \\
\hline CB & 6.76 & 6.90 & 7.30 & 7.36 & 7.18 & $\mathbf{7 . 6 6}$ & 7.3 & 7.62 \\
\hline SNC & 59.37 & 50.29 & 47.02 & 59.64 & 59.87 & 69.97 & 61.47 & $\mathbf{7 0 . 6 7}$ \\
\hline TSW & 1.44 & 1.50 & 1.29 & 1.20 & 1.44 & 1.55 & 1.4 & $\mathbf{1 . 6 3}$ \\
\hline SY & 1.24 & 1.10 & $\mathbf{2 . 2 0}$ & 1.41 & 1.44 & 1.64 & 0.92 & 0.98 \\
\hline
\end{tabular}

Fig.1 Group constellation of 45 sesame genotypes using first two canonical vectors as coordinates

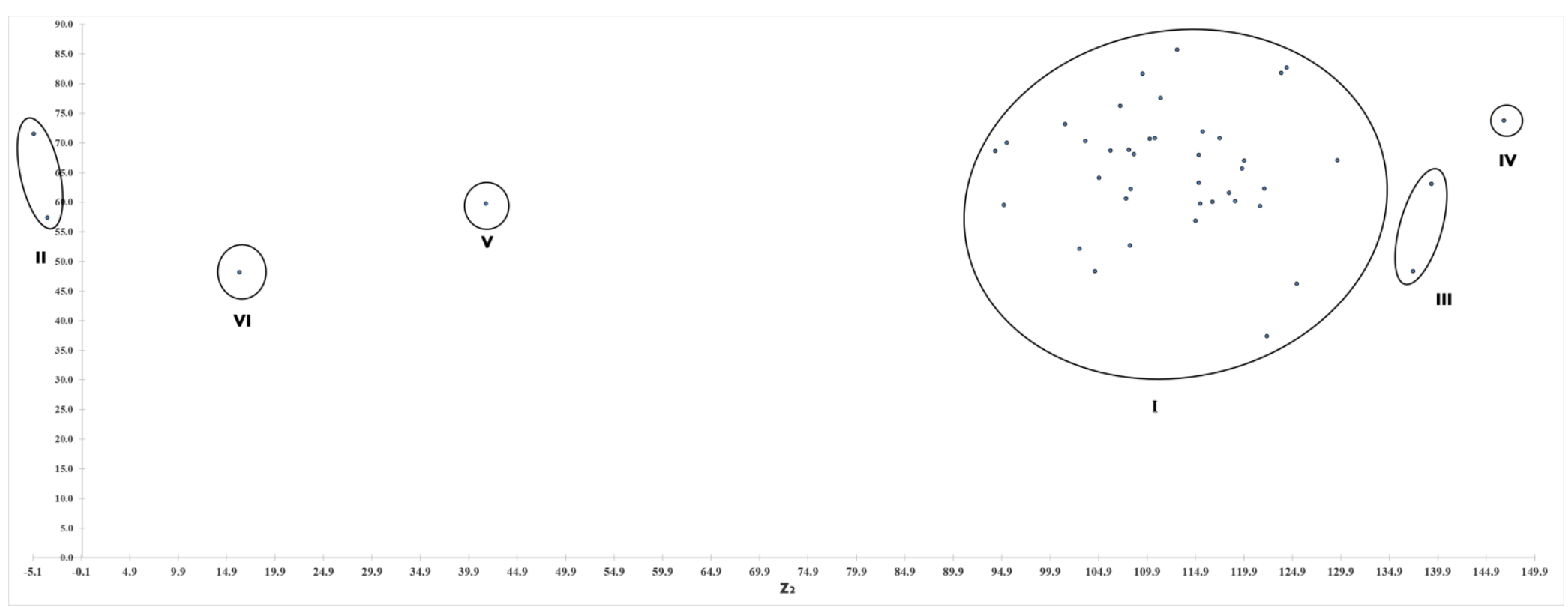


Fig.2 Scattered distribution of the 45 sesame genotypes based on nine traits on the first two principal component axes

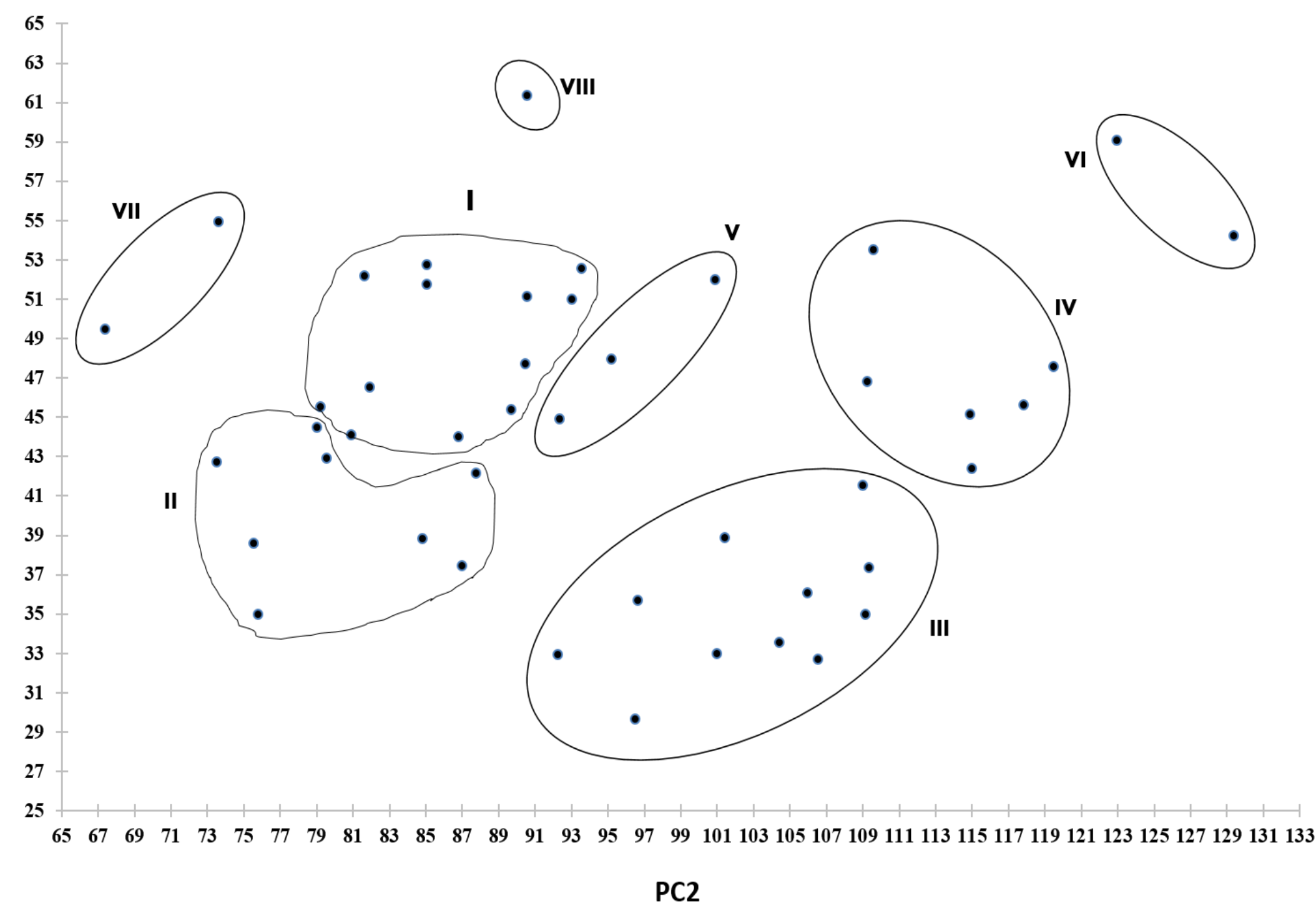


Therefore, depending upon the objective of the breeding programme to derive superior transgressive segregants, hybridization between the selected genotypes from divergent clusters is essential to judiciously combine all the targeted traits.

Relative contribution of different characters to total divergence (Table 3) was assessed through comparison of actual $\mathrm{D}^{2}$ values for individual characters over all possible combinations. It was revealed that capsule width has the highest $(76.86 \%)$ contribution to total divergence $(76.86 \%)$ followed by thousand seed weight $(11.15 \%)$, seed number per capsule $(6.12 \%)$, capsule length $(2.17 \%)$ and seed yield per plant (2.16\%). Total ranks indicated similar trend for the characters. Several reports on character contribution to divergence pertaining to this crop indicate that the contribution of characters to divergence depends on the number of characters studied and the influence of the environment on the expression of characters Chandramohan (2014), Abate and Mekbib (2015), Baraki et al., (2015), Kiranmayi et al., (2016) and Soundharya et al., (2017).

Out of nine characters studied, six characters namely capsule width, thousand seed weight, seed number per capsule and seed yield per plant contributed $98.46 \%$ towards total divergence. Therefore, these characters should be given importance during hybridization and selection of segregating populations.

The canonical analysis for forty five sesame genotypes for nine characters showed that the first two canonical roots were having $80.7 \%$ and $10.3 \%$ of the variability which accounts for $91 \%$ of total variability and thus qualifying for graphic representation. The $Z_{1}$ and $\mathrm{Z}_{2}$ values were used as coordinates in plotting a two dimensional dispersion of genotypic constellation (Fig. 1). The grouping obtained through $\mathrm{D}^{2}$ analysis is superimposed on the constellation by canonical analysis. The scattered points on the $Z_{1}-Z_{2}$ graph were in good agreement with the magnitude of divergence measured by $\mathrm{D}^{2}$ statistic, thus very well corroborating the clustering by Tocher's method.

\section{Divergence studies using principal component analysis}

Principal component analysis is a multivariate statistical method which summarizes the variation in a multivariate sample with fewer variables than the original set with minimal loss of information. It looks for a fewer linear combinations of the attributes/ characters, which gives maximal variance among the genotypes. Principal component analysis (PCA) was carried out by using 45 sesame genotypes and 9 traits. In the present study, the total variability $(99 \%)$ was explained by the first three PCs. This may indicate the contribution of the traits with higher level of correlation to explain the gross diversity. The first and the second PCs explained $97.40 \%$ of the variability, the first being the most important. On the basis of coordinate distance, all the forty five genotypes were grouped into eight clusters of which seven were multi variety clusters and one single variety cluster (Table 4). The lowest intracluster distance of 7.28 was associated with cluster IV, while it was the highest for cluster III (8.52). Average inter-cluster distance varied from 8.14 (between cluster II and V) to 147 (cluster V and VIII).Cluster I, II, IV and VII did not exhibit any extreme values. Cluster III was distinguished for high seed yield per plant. Cluster VI had the distinction of having highest values for branch number per plant, capsule number per plant, plant height and capsule width. Cluster VIII having one genotype had the distinction of having higher values for capsule length, seed number per capsule and thousand seed weight (Table 
5 and Fig. 2). Similar results were reported by Caldo et al., (1996b) and Chakravorty et al., (2013).

The study showed the presence of considerable level of diversity in the genotypes analyzed and the importance morpho-agronomic traits to study genetic diversity. As per $\mathrm{D}^{2}$ statistics the genotypes were clustered into five clusters while PCA grouped them into 8 clusters. Crosses can be made between genotypes of cluster II with genotypes of cluster $\mathrm{V}$ to isolate desirable high yielding segregants. However, crossing between most divergent genotypes may not yield proportionate heterotic response because a cross between extremely divergent parents may create a situation where the harmonious functioning of alleles is somewhat disturbed and consequently the physical functions are not that much efficient as in a situation where the alleles are exposed to similar selection pressure. Parental combinations from the two clusters with higher value of euclidean distance (dissimilarity) coefficient could be used for genetic improvement by crossing.

\section{References}

Abate, M., and Mekbib, F. 2015. Study on genetic divergence in low-altitude sesame (Sesamum indicum L.) germplasm of Ethiopia based on agro morphological traits. Journal of Advanced Studies in Agricultural, Biological and Environmental Sciences. 2(3): 78-90.

Anderson, T. W. 1958. An Introduction to Multivariate Statistical Analysis. John Wiley and Sons, New York.

Anilakumar, K.R., Pal, A., Khanum, F., Bawa, A.S. 2010. Nutritional, medicinal and industrial uses of sesame (Sesamum indicum L.) seeds - an overview. Agric. Conspec. Scientificus. 75 (4):159-168.
Anuradha, T. and Reddy, G. L. K. 2004. Genetic divergence in sesame (Sesamum indicum L.) across three locations in Andhra Pradesh. J. Oilseeds Res. 21: 266-269.

Anuradha, T. and Reddy, G. L. K. 2005. D ${ }^{2}$ analysis in sesame (Sesamum indicum L.). J. Oilseeds Res. 22: 174- 175.

Caldo, R.A., Sebastian, L.S. and Hernandez, J.E. 1996. Morphology-based genetic diversity analysis of ancestral lines of rice in Philippine rice cultivars. Philipp. J. Crop Sci., 21: 86-92.

Chakravorty, A., Ghosh, P.D. and Sahu, P.K. 2013. Multivariate analysis of phenotypic diversity of landraces of rice of West Bengal. Am. J.Exp. Agric., 3: 110-123.

Chandramohan, Y. 2014. Variability and genetic divergence in sesame (Sesamum indicum L.). International Journal of Applied Biology and Pharmaceutical Technology. 5(3): 222-225.

Fiseha B, Yemane T and Fetien A. 2015. Assessing inter-relationship of sesame genotypes and their traits using cluster analysis and principal component analysis methods. International Journal of Plant Breeding and Genetics. 9 (4): 228-237.

Hika, G., Geleta, N. and Jaleta, Z. 2015. Correlation and divergence analysis for phenotypic traits in sesame (Sesamum indicum L.) genotypes. Science Technology and Arts Research Journal. 3(4): 1-09.

Kiranmayi, S. L., Roja V., Padmalatha, K., Sivaraj, $\mathrm{N}$ and Sivaramakrishnan, S.2016. Genetic diversity analysis in sesame (Sesamum indicum) using morphological, biochemical and molecular techniques, IJABFP, 7 (1): 95-110.

Mahalanobis, P.C. 1936. On the generalized distance in statistics. Procurement 
National Institute Science, India, 2: 4955.

Murty, B. R., and Arunachalam, V. 1996. The nature of genetic divergence in relation to breeding system in some crop plants. Ind. J. Genet., 26 (a): 188-198.

Rao, C.R. 1960. Multivariate analysis - an indispensable statistical aid in applied research. Shankya, 22: 317-388.

Saeed Farhan, Qamar, A., Nadeem, M.T., Ahmed, R.S., Arshad, M.S. and Afzaal, M. 2015. Nutritional composition and fatty acid profile of some promising sesame cultivars. Pak. J. Food Sci., 25(2): 98-103.

Singh, R. V. and S. S Bains.1968. Genetic divergence for ginning outurn and its components in upland cotton. Ind. $J$. Genet., 28: 262-269.
Soundharya, B., V. Hemalatha, T., Rani S. and Edukondalu, B. 2017. Genetic divergence studies in sesame (Sesamum indicum L.) genotypes. Int.J.Curr. Microbiol.App.Sci. 6(9): 2615-2619.

Sudhakar, N., Sridevi, O., and Salimath, P.M. 2007. Variability and character association analysis in sesame (Sesamum indicum L.). Journal of Oilseeds Research, 24(1): 56-58.

Tripathi, A., Bisen, R., Ahirwal, P.R., Paroha, S., Sahu, R. and Ranganatha ARG. 2013. Study on genetic divergence in sesame (Sesamum indicum L.) germplasm based on morphological and quality traits. The Bioscan, 8(4): 13871391.

\section{How to cite this article:}

Manasi Dash, Ghanashyam Haibru, Mandakini Kabi, Bansidhar Pradhan, Devraj Lenka and Sapan Kumar Tripathy. 2018. Morphology-Based Genetic Diversity Analysis of Sesame Germplasm for Yield and Capsule Characters. Int.J.Curr.Microbiol.App.Sci. 7(09): 1817-1826. doi: https://doi.org/10.20546/ijcmas.2018.709.221 